\title{
Diagnostic value of the hamstring to quadriceps ratio in monitoring of the effectiveness of supervised 6-month physiotherapy in males after Anterior Cruciate Ligament Reconstruction (ACLR)
}

\author{
KATARZYNA KRZEMIŃSKA ${ }^{1 *}$, ANDRZEJ CZAMARA ${ }^{2}$ \\ ${ }^{1}$ Centre of Rehabilitation and Medical Education, Wrocław, Poland. \\ ${ }^{2}$ College of Physiotherapy in Wroclaw, Wrocław, Poland.
}

\begin{abstract}
Purpose: The aim of the study was to assess the usefulness of isometric torque (IT) and peak torque (PT) of the hamstring to quadriceps muscles ratio (H/Q ratio) in monitoring the effectiveness of physiotherapy (PH) in males after ACLR. Hypothesis: The H/Q ratio is a diagnostic tool for monitoring of the effectiveness of the 6- month PH after ACLR. Methods: Twenty males 6 months after ACLR (ACLR group) and 20 male controls underwent IT and PT $(60 \%$ and $180 \%$ s) bilateral measurements of H and Q muscles. The IT and PT were normalized to body mass, and expressed as relative IT (RIT) and relative PT (RPT). The RIT and RPT H/Q ratios, and Limb Symmetry Index (LSI) were calculated. Results: In the ACLR group, the RIT for the H and Q, the RIT for the H/Q ratio and most of the RPT, as well as the $\mathrm{H} / \mathrm{Q}$ ratio, ROM and LSI values of the operated knee, were not significantly different (NSD) than those of the non-operated side (NOS) or the control group. The between-group comparison of the H/Q ratio for RIT and RPT weren't NSD. The isokinetic test at $180 \%$ s showed lower RPT, H/Q ratio and LSI values for the Q muscle than those of the NOS $(p=0.042, p=0.001)$. Conclusions: The H/Q ratio, in combination with the RIT, RPT and LSI, is a useful diagnostic tool for monitoring the effectiveness of 6-month PH after ACLR. Restoring the correct $\mathrm{H} / \mathrm{Q}$ ratio can reduce the risk factor for $\mathrm{ACL}$ graft rupture.
\end{abstract}

Key words: prevention, isokinetic, symmetry index, motion, isometry

\section{Introduction}

The hamstring to quadriceps ratio (also called the $\mathrm{H} / \mathrm{Q}$ ratio) is used for assessing the reciprocal strength of the hamstring and quadriceps muscles [14], [26]. It is typically utilized by athletes preparing for competitions and by therapists during physical therapy after knee joint injuries. The H/Q ratio is considered to be a screening tool for predisposition to knee injuries. During rehabilitation after a knee injury, the H/Q is used as a target reference due to the importance of having a balanced flexor-to-extensor ratio in stabilizing the knee joint [10]. The usefulness of the H/Q ratio has been assessed in athletes practicing contact sports, which are characterized by quick changes in the direction of movement and have a high rate of knee joint injuries [22], [25]. The H/Q ratio has been utilized as a predictor for knee joint injuries, accounting for the patient's gender and age [7], [8], [13], [20]. It has also been used in graft assessment for ACLR [9] and in the assessment of long-term outcomes of knee joint treatments [28]. There are few papers confirming or excluding the usefulness of the H/Q ratio in monitoring consecutive stages of supervised physical therapy in patients who have had ACL injuries [2], [5]. The H/Q torque ratio is also important because one of the main goals of physiotherapy is to restore muscle strength and normal biomechanical muscle balance in the operated knee joint. Kyritsis et al. [16] reported

\footnotetext{
* Corresponding author: Katarzyna Krzemińska, College of Physiotherapy in Wroclaw, ul. Tadeusza Kościuszki 4, 50-038 Wrocław. Phone: +48 694845127, e-mail: katarzyna.krzeminskaa@gmail.com

Received: May 31st, 2020

Accepted for publication: August 5th, 2020
} 
criteria for returning to sport after ACLR, one of which was the strength of knee joint muscles. In the study, the authors demonstrated that deficits in the H/Q strength ratio were associated with an increased risk of rupturing the ACL graft [16].

The aims of the present study were to assess the usefulness of isometric torque (IT) and the isokinetic peak torque (PT) of the hamstring to quadriceps ratio (H/Q ratio) and to assess such parameters as the symmetry index, ROM and pain in monitoring the effectiveness of a 24-week supervised postoperative physiotherapy regimen (SVPh) in males who have undergone ACLR and who want to return to their sport.

\section{Materials and methods}

\subsection{Participants}

The postoperative physiotherapy and tests were carried out in accordance with the Declaration of Helsinki at the Center of Rehabilitation and Medical Education and the College of Physiotherapy in Wroclaw. All participants were informed about the aims of the study and provided their written informed consent form for participation. A written consent was obtained from the Senate Research Ethics Committee of the College of Physiotherapy in Wroclaw.

The criteria for inclusion and exclusion are given in Fig. 1. From the initial number of 90 patients after
ACLR, after the conditions of exclusion from the study, 20 people who had isolated total ACL rupture were selected. Thus, they did not have significant coexistence damage, which would require surgical treatment. We tried to choose the most homogeneous group for greater reliability of research.

Table 1. Characteristics of the study participants

\begin{tabular}{|l|c|c|c|c|c|c|}
\hline \multirow{1}{*}{$\begin{array}{c}\text { Testing } \\
\text { group }\end{array}$} & \multicolumn{2}{|c|}{$\begin{array}{c}\text { Age } \\
\text { [years] }\end{array}$} & \multicolumn{2}{c|}{$\begin{array}{c}\text { Body mass } \\
{[\mathrm{kg}]}\end{array}$} & \multicolumn{2}{c|}{$\begin{array}{c}\text { Body height } \\
{[\mathrm{cm}]}\end{array}$} \\
\cline { 2 - 7 } & $x$ & $\mathrm{SD}$ & $x$ & $\mathrm{SD}$ & $x$ & SD \\
\hline $\begin{array}{l}\text { ACLR group } \\
{[n=20]}\end{array}$ & 27.80 & 5.48 & 82.75 & 9.00 & 183.60 & 7.83 \\
\hline $\begin{array}{l}\text { Control group } \\
{[n=20]}\end{array}$ & 24.85 & 3.12 & 82.95 & 9.16 & 181.85 & 5.45 \\
\hline$p$ & \multicolumn{2}{|c|}{0.88} & \multicolumn{2}{|c|}{0.30} & \multicolumn{2}{c|}{0.76} \\
\hline
\end{tabular}

ACLR - anterior cruciate ligament reconstruction; SD - standard deviation; $n$ - number of individuals; $x$ - arithmetic mean, $p$-significance level.

Based on the exclusion criteria, 20 males who have undergone ACLR qualified for the study. Participants were athletes after primary unilateral ACLR using semitendinosus (ST) or semitendinosus and gracilis (STGR) muscles tendons, harvested from the operated leg. Participants' physical activity levels before injury were ranked as level 7 in the Tegner Activity Level Scale (TAS). The patients underwent a supervised minimum 24 weeks of four-staged postoperative physiotherapy with a physiotherapist from the Center of Rehabilitation and Medical Education and were

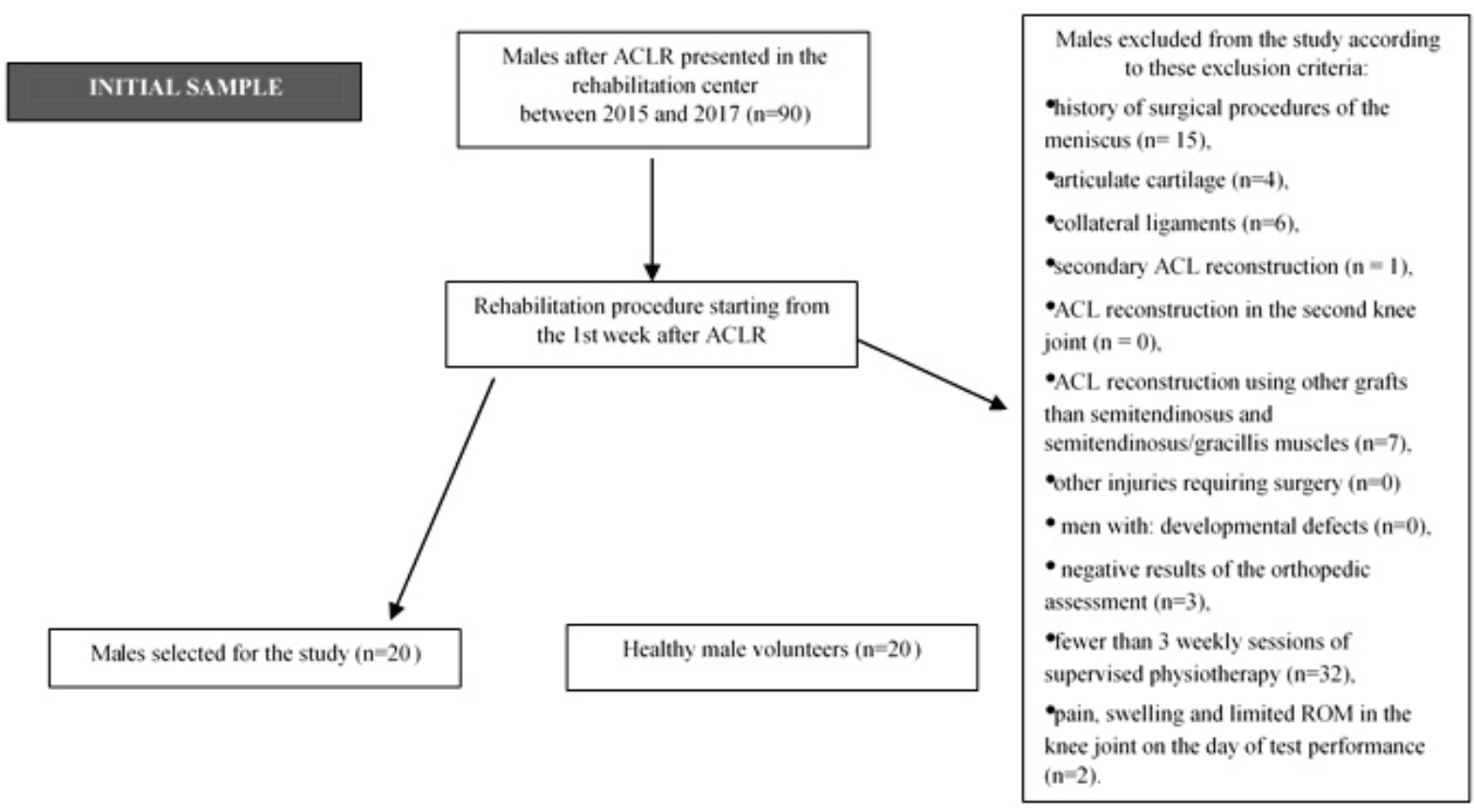

Fig. 1. Flowchart of the study 
assigned to the ACLR group $(n=20)$. The supervised physiotherapy sessions were held 3 times a week for 2 hours per session. The control group included male athletes (with a TAS physical activity level of 7) without knee joint injuries $(n=20)$. Table 1 presents the detailed anthropometric characteristics of the two groups. There were no statistically significant differences in age, body mass and body height between the two groups.

\subsection{Surgical procedure}

Arthroscopy was carried out using standard anteromedial (AM) and anterolateral (AL) operative access. The primary unilateral ACL reconstruction was performed using ST $(n=3)$ or STGR $(n=17)$ grafts. Graft fixation was performed using standard stabilizing methods. All patients were operated on by the same two senior orthopedic surgeons.

\subsection{Postoperative physiotherapeutic procedure}

ACLR patients underwent a four-stage supervised postoperative physiotherapy regimen (lasting a minimum of 24 weeks and a maximum of 32 weeks), that has been previously described [2], [5]. The patients also had to perform learned exercises at home. The main goals of stage I (1-5 weeks postoperatively) were to eliminate the side effects of the early postoperative period, restore ROM in the operated knee joint, and perform isometric exercises, proprioception exercises and gait training with partial unloading of the operated lower limb. Stage II (6-12 weeks postoperatively) included a continuation of the workout from stage I, an active workout of the muscles affecting the operated knee joint, resistance exercises for the large groups of lower limb muscles beyond the area of the operated knee joint and exercises on a cycle ergometer. The degree of difficulty of the proprioception exercises was increased by using an unstable surface. Walking without crutches was introduced at the end of Stage II. During stage III (from 13th to 20th week postoperatively), patients began monitored isometric training with gradual quadriceps femoris resistance in the operated leg. After reaching $70 \%$ strength in the quadriceps and hamstring muscles of the operated knee joint and ground reaction force (corresponding to 2.5 times their body mass on a tensometric platform during a one leg jump), jogging and then running on a treadmill were gradually introduced.
Next, jumping and plyometric exercises were introduced, as well as movement coordination exercises and operational movement techniques, which were individually chosen for each patient. After the 16th week, strength training was initiated under isokinetic conditions for the extensor and flexor muscles of the knee joint, within a limited ROM. The goal of stage IV (21 weeks to 6-8 months postoperatively) was recovery and compensation of strength, developing jumping ability, speed and agility, dynamic proprioception and maximizing patient's physical capacity. The introduced exercises were specific to the given sport discipline or occupational activity of each athlete [2], [5].

\subsection{Measurement approaches}

Six months after ACLR (ACLR group) and the Control group underwent IT and PT $(60 \%$ s and $180 \%$ s) bilateral measurements of $\mathrm{H}$ and $\mathrm{Q}$ muscles. Maximal Isometric Torque (IT) assessments were carried out during isometric tests of the quadriceps $(\mathrm{Q})$ and hamstring $(\mathrm{H})$ muscles. In both groups, each workout was preceded by a 12-minute warm up on a cycle ergometer for each leg. Isometric tension was maintained for 10 seconds, and there was a 2-minute interval between the first and second repetitions. IT measurements were started in the quadriceps muscles, next, the patient changed positions and IT values were measured in hamstring muscles. The highest IT values were selected for further analysis. On the same day, after a 15-minute rest, maximal torque was measured using an isokinetic test. In the test, the maximal peak torque (PT) values of quadriceps and hamstring muscles of the knee joint were measured [N.m]. Range of motion (ROM) values, expressed in $\left[{ }^{\circ}\right]$, were also measured, according to previously described research method [4]. Measurements were taken in a seated position using HUMAC NORM Testing \& Rehabilitation System (CSMI Computer Sports Medicine, Inc., Stoughton, MA, USA). Two angular velocities were applied during the measurements, specifically $60 \%$ (5 repetitions) and $180 \% \mathrm{~s}$ (8 repetitions) with a 2-minute interval between the series of measurements [9]. In the ACLR group, the IT and PT measurements were taken immediately after the 24th postoperative week. In the Control group, IT, PT and ROM were measured once, first for the right and then for left of the knee, while in the ACLR group, they were first measured in the uninvolved knee joints and then in the operated knee.

The IT H/Q ratio was calculated by dividing the IT value obtained from the knee flexor muscles by 
the IT value of the knee extensor muscles: IT $\mathbf{H} / \mathbf{Q}$ ratio $=\frac{\text { RIT hamstring muscles }(\mathrm{H})}{\text { RIT quadriceps muscles }(\mathrm{Q})}$. The PT H/Q ratio was calculated by dividing the $\mathrm{PT}$ value obtained in knee flexor muscles by the PT value of the knee extensor muscles: $\mathbf{P T} \mathbf{H} / \mathbf{Q}$ ratio $=$ RPT hamstring muscles $(\mathrm{H})$ RPT quadriceps muscles $(\mathrm{Q})$.

The Limb Symmetry Index (LSI) was used to assess the symmetry level of values, such as the RIT and RPT of the lower limbs and to compare the results between the two groups. In the ACLR group, the LSI under isomeric and isokinetic conditions, respectively, was calculated using the following formulas,

\subsection{Statistical analysis}

Statistical analyses were conducted using SPSS Statistical software, vol. 20. The PT and IT values were normalized to body mass and expressed as relative PT, RPT $\left(\mathrm{N} \cdot \mathrm{m}^{\mathrm{kg}} \mathrm{kg}^{-1} \mathrm{bm}\right)$ and relative IT, RIT $\left(\mathrm{N} \cdot \mathrm{m} \cdot \mathrm{kg}^{-1} \mathrm{bm}\right)$, respectively. The arithmetic mean (x) and standard deviations (SD) were calculated for each variable. The distributions of the studied variables was analyzed using Shapiro-Wilk normality tests. Statistical significance of between-subject differences were assessed using Wilcoxon signed rank tests, while between-group differences were measured using MannWhitney $U$-tests for independent samples. For the

$$
\begin{aligned}
& \mathrm{LSI}=\frac{\text { RIT quadriceps or hamstring muscles of the operated knee joint }}{\text { RIT quadriceps or hamstring muscles of the nonoperated knee joint }} * 100, \\
& \text { LSI }=\frac{\text { RPT quadriceps or hamstring muscles of the operated knee joint }}{\text { RPT quadriceps or hamstring muscles of the nonoperated knee joint }} * 100 .
\end{aligned}
$$

The same formula was applied in the control group for the left and right leg. The LSI is a measure of strength as a function of the operated limb with respect to the non-operated limb. The LSI values are commonly used for strength tests in patients after ACLR to calculate the inter-limbs difference, with values lower than 90 commonly being considered as a cut off for return to sport [27].

Before each test, a 100-millimeter Visual Analogue Scale (VAS) was used to assess pain intensity prior to the measurement [1]. Measurement were stopped when pain occurred during the measurement. comparison of the independent samples, ANOVAs were used with Tukey's post-hoc tests. Statistical significance was set at $p<0.05$.

\section{Results}

Twenty-four weeks post-operation, the RIT $(0 \%)$ and RPT values of the ACLR group achieved an angular velocity of $60 \%$, which was similar to those obtained from the non-operated side for both studied

Table 2. The RIT values from the isometric test $(0 \%)$ in the ACLR group and the RPT values

\begin{tabular}{|c|c|c|c|c|c|c|c|}
\hline \multirow{3}{*}{ TEST } & \multirow{3}{*}{$\begin{array}{l}\text { Angular } \\
\text { velocity }\end{array}$} & \multicolumn{3}{|c|}{ RIT and RPT $\left(\mathrm{N} \cdot \mathrm{m} \cdot \mathrm{kg}^{-1} \mathrm{bm}\right)$ in the ACLR group } & \multicolumn{3}{|c|}{ RIT and RPT $\left(\mathrm{N} \cdot \mathrm{m} \cdot \mathrm{kg}^{-1} \mathrm{bm}\right)$ in the control group } \\
\hline & & \multicolumn{2}{|c|}{ Quadriceps muscles of the knee joint } & \multirow{2}{*}{$p$} & \multicolumn{2}{|c|}{ Quadriceps muscles of the knee joint } & \multirow{2}{*}{$p$} \\
\hline & & Operated & Non-operated & & Right & Left & \\
\hline Isometric & $0 \% \mathrm{~s}$ & $3.72 \pm 0.95$ & $3.86 \pm 0.97$ & 0.139 & $3.71 \pm 0.87$ & $3.78 \pm 0.93$ & 0.313 \\
\hline \multirow{2}{*}{ Isokinetics } & $60 \%$ & $2.56 \pm 0.56$ & $2.71 \pm 0.48$ & 0.080 & $2.63 \pm 0.45$ & $2.46 \pm 0.27$ & 0.026 \\
\hline & $180 \% \mathrm{~s}$ & $1.81 \pm 0.40$ & $2.06 \pm 0.31$ & $\leq 0.001$ & $1.89 \pm 0.30$ & $1.83 \pm 0.27$ & 0.111 \\
\hline \multirow{2}{*}{ TEST } & \multirow{2}{*}{$\begin{array}{l}\text { Angular } \\
\text { velocity }\end{array}$} & \multicolumn{2}{|c|}{ Hamstring muscles of the knee joint } & \multirow{2}{*}{$p$} & \multicolumn{2}{|c|}{ Hamstring muscles of the knee joint } & \multirow{2}{*}{$p$} \\
\hline & & Operated & Non-operated & & Right & Left & \\
\hline Isometric & $0 \% \mathrm{~s}$ & $1.51 \pm 0.38$ & $1.63 \pm 0.33$ & 0.099 & $1.71 \pm 0.37$ & $1.61 \pm 0.44$ & 0.070 \\
\hline \multirow{2}{*}{ Isokinetics } & $60 \% \mathrm{~s}$ & $1.55 \pm 0.30$ & $1.65 \pm 0.25$ & 0.055 & $1.56 \pm 0.26$ & $1.51 \pm 0.33$ & 0.209 \\
\hline & $180 \% \mathrm{~s}$ & $1.16 \pm 0.24$ & $1.24 \pm 0.21$ & 0.023 & $1.08 \pm 0.22$ & $1.07 \pm 0.19$ & 0.643 \\
\hline
\end{tabular}
from the isokinetic tests $(60 \% \mathrm{~s}$ and $180 \%$ s) for the individual tests and the control group

ACLR - group after anterior cruciate ligament reconstruction, Control group - participants with no injuries in the musculoskeletal system $x$ - arithmetic mean, $p$ - statistical significance level, RIT - relative isometric torque obtained under conditions of isometric toning, expressed in $\mathrm{kg}$ of body mass a $\left(\mathrm{N} \cdot \mathrm{m} \cdot \mathrm{kg}^{-1} \mathrm{bm}\right), \mathrm{RPT}$ - peak torque obtained in isometric conditions, expressed in $\mathrm{kg}$ of body mass $\left(\mathrm{N} \cdot \mathrm{m} \cdot \mathrm{kg}^{-1} \mathrm{bm}\right)$. 
groups of muscles. The differences were statistically insignificant (Table 2).

Lower RPT values for the Q and $\mathrm{H}$ muscles were maintained at an angular velocity of $180 \%$, compared with the non-operated side. The differences were statistically significant, however, the LSI values were above $90 \%$ and insignificant from a clinical perspective (Table 4). The trend observed in the ACLR group was similar to that noted in the control group, where five of the six measurement results did not show significant differences between the RIT and RPT values in the studied muscle groups, compared to the left knee joints (Table 2).

In the ACLR group, differences in the 24-week postoperative $\mathrm{H} / \mathrm{Q}$ ratio for RIT $(0 \% \mathrm{~s})$ and the H/Q ratio for RPT $(60 \%)$ between the operated knee joints and the non-operated knee joints were not statistically significant (Table 3 ). In addition, the cut-off values of the differences in the H/Q ratio for RPT $(180 \%)$, which bordered statistical significance, were noted only at an angular velocity of $180 \%$ s.

There were no statistically significant differences between groups for the H/Q ratio for RIT $(0 \%)$ ) or for RPT $(60 \%$ and $(180 \%)$ between the operated knee joints in the ACLR group and the right and left knee joints in the control group (Fig. 2).

After 24 weeks, there were no significant differences in the LSI for RIT $(0 \% \mathrm{~s})$ and RPT $(60 \%)$ measurements of quadriceps and hamstring muscles of the ACLR group compared to the control group. The only statistically significant differences were observed in the quadriceps muscles in the isokinetic test at a velocity of $180 \%$ s (Table 4 ).

Table 3. The H/Q ratio values obtained in the ACLR group in the isometric test and in the isokinetic test for each measurement and in the control group

\begin{tabular}{|c|c|c|c|c|c|c|c|}
\hline \multirow{3}{*}{ TEST } & \multirow{3}{*}{$\begin{array}{l}\text { Angular } \\
\text { velocity }\end{array}$} & $\mathrm{AC}$ & group & \multirow{3}{*}{$p$} & Cont & group & \multirow{3}{*}{$p$} \\
\hline & & \multicolumn{2}{|c|}{ Studied knee H/Q ratio [\%] } & & Studied kne & $\mathrm{H} / \mathrm{Q}$ ratio $[\%]$ & \\
\hline & & Operated & Non-operated & & Right & Left & \\
\hline Isometric & $0 \% \mathrm{~s}$ & $0.42 \pm 0.12$ & $0.45 \pm 0.13$ & 0.339 & $0.48 \pm 0.13$ & $0.45 \pm 0.16$ & 0.057 \\
\hline \multirow{2}{*}{ Isokinetics } & $60 \% \mathrm{~s}$ & $0.62 \pm 0.11$ & $0.62 \pm 0.10$ & 0.852 & $0.58 \pm 0.10$ & $0.59 \pm 0.08$ & 0.511 \\
\hline & $180 \% \mathrm{~s}$ & $0.65 \pm 0.11$ & $0.60 \pm 0.09$ & 0.042 & $0.60 \pm 0.08$ & $0.62 \pm 0.09$ & 0.276 \\
\hline
\end{tabular}

ACLR - group after anterior cruciate ligament reconstruction, Control group - participants with no injuries in the musculoskeletal system $x$ - arithmetic mean, $p$ - statistical significance level, H/Q ratio - reciprocal relations between the biomechanical parameters of the hamstring to quadriceps [\%].

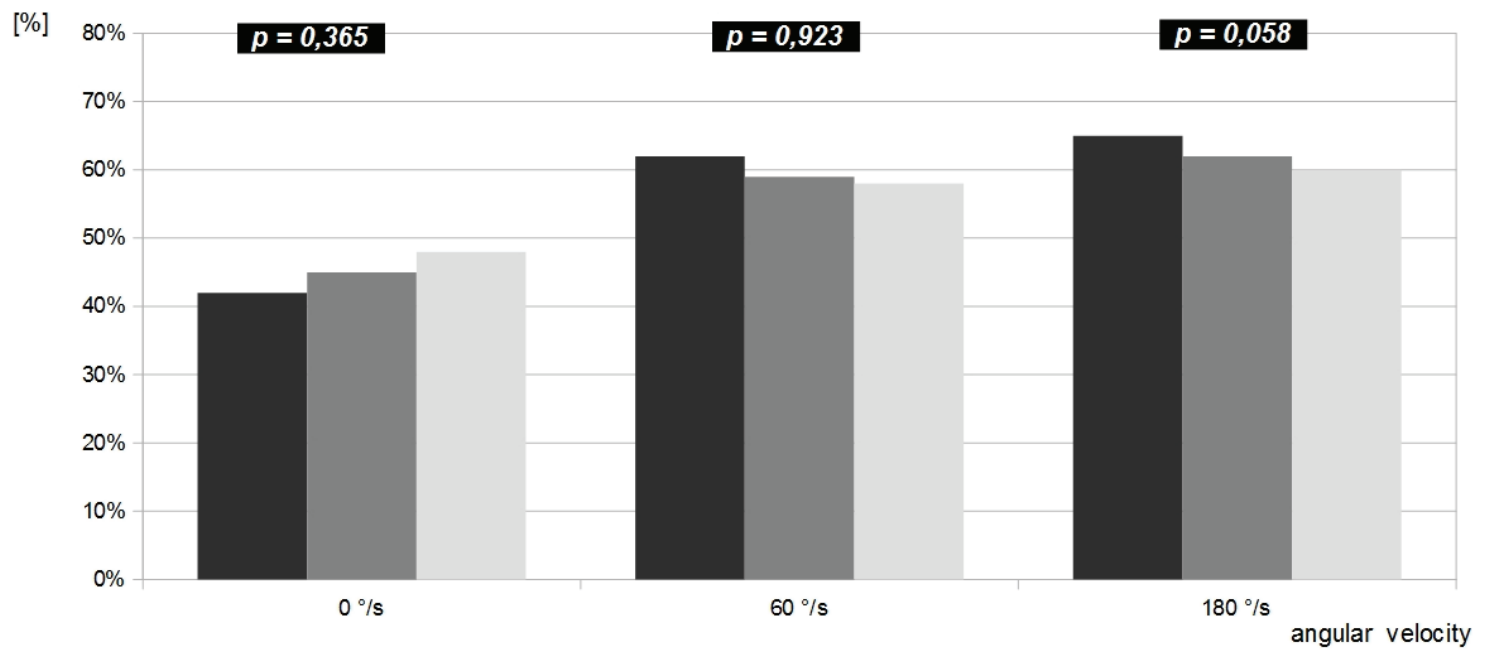

- ACLR Group: operaterd knee joint $\quad$ - Control Group: left knee joint $\quad$ Control Group: right knee joint

Fig. 2. Comparison of the H/Q ratio obtained in the operated knee joint (I) in the ACLR group during the isometric test and in the isokinetic test for the left (II) and right (III) knee joint measurements in the control group 
No pain was reported on the VAS scale in either group (Table 5).

The measurement of flexion and extension (ROM) in the knee joints during the isokinetic tests showed no statistically significant differences between the studied knee joints in either groups. There was a statistically significant difference in knee joint flexion between the operated and the non-operated knee joints of the ACLR group $\left(4.5^{\circ}\right.$, difference less than $\left.4 \%\right)$, but the differences were insignificant from clinical point of view (Table 6).

Table 4. Differences in the LSI for RIT and RPT during the isometric and isokinetic tests, between the ACLR and control groups 24-weeks postoperation.

\begin{tabular}{|c|c|c|c|c|c|c|c|}
\hline \multicolumn{7}{|c|}{ Limb Symmetry Index (LSI) expressed in \% for RIT and RPT } \\
\hline \multirow{2}{*}{ Test } & \multirow{2}{*}{$\begin{array}{c}\text { Angular } \\
\text { velocity }\end{array}$} & \multicolumn{2}{|c|}{ Quadriceps muscles } & \multirow{2}{*}{$p$} & \multicolumn{2}{|c|}{ Hamstring muscles } & \multirow{2}{*}{$p$} \\
\cline { 3 - 4 } \cline { 6 - 8 } & & ACLR group & Control group & & ACLR group & Control group & \\
\hline Isometric & $0 \% / \mathrm{s}$ & $96.89 \pm 12.11$ & $101.85 \pm 8.20$ & 0.079 & $93.83 \pm 20.12$ & $94.19 \pm 12.71$ & 0.970 \\
\hline \multirow{2}{*}{ Isokinetics } & $60 \% \mathrm{~s}$ & $94.92 \pm 13.73$ & $93.95 \pm 11.25$ & 0.478 & $93.90 \pm 13.29$ & $96.58 \pm 10.74$ & 0.510 \\
\cline { 2 - 4 } & $180 \% / \mathrm{s}$ & $87.50 \pm 11.29$ & $97.10 \pm 8.32$ & 0.030 & $93.85 \pm 11.24$ & $99.89 \pm 12.71$ & 0.133 \\
\hline
\end{tabular}

ACLR group - group after anterior cruciate ligament reconstruction; Control group - participants with no injuries in the musculoskeletal system, \pm- standard deviation, $x$ - arithmetic mean, $p$ - statistical significance level, LSI - Limb Symmetry Index for RIT and RPT.

Table 5. Pain measured using the VAS scale in the ACLR group during the isometric and isokinetic tests and in the control group

\begin{tabular}{|c|c|c|c|c|c|c|c|}
\hline \multicolumn{8}{|c|}{ 100-millimeter Visual Analog Scale (VAS) } \\
\hline \multirow{3}{*}{ Test } & \multirow{3}{*}{$\begin{array}{l}\text { Angular } \\
\text { velocity }\end{array}$} & \multirow{2}{*}{\multicolumn{2}{|c|}{$\frac{\text { ACLR group }}{\text { Studied knee }}$}} & \multirow{3}{*}{$p$} & \multirow{2}{*}{\multicolumn{2}{|c|}{$\frac{\text { Control group }}{\text { Studied knee }}$}} & \multirow{3}{*}{$p$} \\
\hline & & & & & & & \\
\hline & & Operated & Non-operated & & Right & Left & \\
\hline Isometric & $0 \% \mathrm{~s}$ & 0.00 & 0.00 & $\mathrm{n} / \mathrm{a}$ & 0.00 & 0.00 & $\mathrm{n} / \mathrm{a}$ \\
\hline \multirow{2}{*}{ Isokinetics } & $60 \% \mathrm{~s}$ & 0.00 & 0.00 & $\mathrm{n} / \mathrm{a}$ & 0.00 & 0.00 & $\mathrm{n} / \mathrm{a}$ \\
\hline & $180 \% \mathrm{~s}$ & 0.00 & 0.00 & $\mathrm{n} / \mathrm{a}$ & 0.00 & 0.00 & $\mathrm{n} / \mathrm{a}$ \\
\hline
\end{tabular}

ACLR - group after anterior cruciate ligament reconstruction, Control group - participants with no injuries in the musculoskeletal system, $x$ - arithmetic mean, $p$ - statistical significance level, VAS - Visual Analogue Scale - pain assessment scale.

Table 6. Range of motion (ROM) of knee flexion and extension in the isokinetic velocities of $180 \% \mathrm{~s}$ and $60 \% \mathrm{~s}$ in the ACLR and control groups

\begin{tabular}{|c|c|c|c|c|c|c|}
\hline \multicolumn{7}{|c|}{ ROM $180^{\circ} / \mathrm{S}$} \\
\hline \multirow{2}{*}{ Testing group } & \multicolumn{2}{|c|}{ Knee joint extension } & \multirow{2}{*}{$p$} & \multicolumn{2}{|c|}{ Knee joint flexion } & \multirow{2}{*}{$p$} \\
\hline & Operated & Uninvolved & & Operated & Uninvolved & \\
\hline ACLR group & $1.45 \pm 3.10$ & $2.10 \pm 1.62$ & 0.545 & $109.45 \pm 6.77$ & $112.75 \pm 7.31$ & 0.073 \\
\hline \multirow{2}{*}{ Control group } & Right & Left & $p$ & Right & Left & $p$ \\
\hline & $1.35 \pm 1.04$ & $2.05 \pm 1.67$ & 0.184 & $106.60 \pm 8.23$ & $108.80 \pm 9.13$ & 0.254 \\
\hline \multicolumn{7}{|c|}{ ROM $60^{\circ} / \mathrm{S}$} \\
\hline \multirow{2}{*}{ Testing group } & \multicolumn{2}{|c|}{ Knee joint extension } & & \multicolumn{2}{|c|}{ Knee joint flexion } & \multirow{2}{*}{$p$} \\
\hline & Operated & Uninvolved & $p$ & Operated & Uninvolved & \\
\hline ACLR group & $2.65 \pm 4.17$ & $2.75 \pm 3.16$ & 0.873 & $108.70 \pm 7.81$ & $113.15 \pm 7.13$ & 0.012 \\
\hline \multirow{2}{*}{ Control group } & Right & Left & $p$ & Right & Left & $p$ \\
\hline & $4.20 \pm 5.04$ & $5.60 \pm 6.04$ & 0.218 & $105.75 \pm 10.07$ & $107.90 \pm 10.57$ & 0.203 \\
\hline
\end{tabular}

ACLR group - group after anterior cruciate ligament reconstruction, Control group - participants with no injuries in the musculoskeletal system, \pm- standard deviation, $x$ - arithmetic mean; $p$ - statistical significance level, $\mathrm{ROM}$ - Range of motion $\left[{ }^{\circ}\right]$ of the knee during isokinetic tests. 


\section{Discussion}

The present study suggests that the operated knee joints of the ACLR group achieved values similar to those obtained from the non-operated knee joints and those of the Control Group after 24-weeks postoperatively for most of the measured biomechanical parameters (RIT, RPT, H/Q ratio, LSI and ROM). The $\mathrm{H} / \mathrm{Q}$ ratios in the isometric and isokinetic tests were similar to those obtained in the non-operated knees and in the control group. The results show that the $\mathrm{H} / \mathrm{Q}$ ratio is a useful diagnostic parameter for monitoring the effectiveness of regular, 6-month supervised physiotherapy in patients after ACLR, especially when combined with analysis of real RIT, RPT and ROM values. The results also suggest that this method is also characterized by a lack of pain in the operated knee joints.

There are numerous publications confirming the diagnostic value of the H/Q torque ratio [6], [19]. In a meta-analysis by Kim et al. [15], the authors hypothesized that despite a decrease in the quadriceps and ischiocrural muscle group strength due to an ACL tear, the $\mathrm{H} / \mathrm{Q}$ ratio is be relatively unchanged compared to the corresponding value from the nonoperated leg due to the decrease in strength in both muscle groups. In a retrospective study carried out in 53 patients after ACLR, Haillotte et al. [12] showed that though differences in quadriceps strength of approximately $15 \%$ persisted compared to the nonoperated leg at 24-weeks post operation, the values of the H/Q ratio were normal and similar to the normal physiological state. Some authors have reported that the H/Q ratio is not a good diagnostic parameter in the assessment of physiotherapy progress or sport training [23]. Lee et al. [17] conducted isokinetic tests in 25 patients after ACLR and 25 patients with no injuries to the musculoskeletal system. The ACLR patients had significantly lower absolute torque values in the hamstring and quadriceps muscles of the knee joint and $\mathrm{H} / \mathrm{Q}$ ratio values close to the corresponding values in the control group. Thus, the conclusion was that the H/Q ratio is not a good diagnostic parameter. Moreover, the cited paper did not present any information on the physical therapy process or the adherence of ACLR patients to the physiotherapy sessions. Likewise, Grygorowicz et al. [11] assessed the sensitivity and justifiability of the conducted tests based on 340 reports on isokinetic studies in professional soccer players. The authors concluded that the $\mathrm{H} / \mathrm{Q}$ ratio is of no diagnostic value. However, due to the uniformity of the study sample (only professional soccer players), it is difficult to assess the usefulness of this ratio in monitoring physiotherapy procedures after ACLR. Oliveira et al. [21] used the H/Q ratio to assess the effect of Human Immunodeficiency Virus on knee joint flexor and extensor strength. This was found to be useful in the assessment of muscle strength asymmetry between the lower limbs in patients subjected to isokinetic tests.

Why is it so important to restore the correct $\mathrm{H} / \mathrm{Q}$ ratio for the strength of the knee joint flexor-toextensor muscles after ACLR? In the present study, the ACLR group received grafts to reconstruct the ligament with tendon flexor muscles in the surgical knee, resulting in a reduction in the strength of these muscle groups. In addition, quadriceps strength in the operated knee was reduced by the injuries and the surgery. During the first two stages of postoperative physiotherapy, it was, therefore, necessary to limit the active exercises performed with resistance in the quadriceps muscle in the open kinematic chain of the operated knee joint in order to avoid excessive shear force on the reconstructed anterior cruciate ligament [5]. In the last stage of postoperative physiotherapy, is important to restore muscle strength in the operated knee joints and a proper muscular balance. Specifically, it is critical to restore the so-called biomechanical flexor-to-extensor ratio of the peak torque values in the involved knee joints [5]. Restoring biomechanical parameters and neuromuscular coordination between the extensor and flexor muscle ratio of the isometric and peak torque values in the operated knee joint can decrease the shear force affecting the anterior cruciate ligament (ACL). This is particularly true within the last twenty or so degrees of extension in the open kinematic chain. This means that strong muscle flexors and a correct $\mathrm{H} / \mathrm{Q}$ ratio similar to that in the non-operated side or to those from control subjects protect the ACLR graft from damage. According to Kyritsis et al. [16], deficits in the hamstring-to-quadriceps strength ratio are associated with an increased risk of an anterior cruciate graft rupture. Lee et al. [18] demonstrated that deficits in the hamstring to quadriceps ratio and hamstring strength increase the risk for hamstring strain injury during soccer [18].

This study had some limitations. Measurements were only performed in patients who had received ACLR and who participated in a regular, systematic supervised physiotherapy program for 6 months ( 3 times a week), led by a specialized physical therapist. The patients also had to perform learned exercises at home. The results were not compared to values obtained for patients who participated in fewer or less-regular su- 
pervised physiotherapy sessions. Making such comparisons may allow for more critical evaluation of the effect of some vital factors, including the influence of the number of physiotherapy sessions attended or the frequency and regularity of supervised physiotherapy sessions attended on $\mathrm{H} / \mathrm{Q}$ ratio values. It would also enable more comprehensive assessment of the usefulness of the H/Q ratio for monitoring the progress of physiotherapy [3]. Another limitation concerns the measurements that were performed only in one plane of motion and the analysis of only the relative torque values for the studied groups of muscles and the H/Q ratio [3]. The analyzed parameters should also be assessed regarding power values, mean work, mean power and the time of PT development. This is important since work values have an impact on the torque values in each repetition, the total number of movement repetitions in the isokinetic test, and the full range of motion (the path of covered movement). Moreover, future studies should introduce biomechanical measurements in the transverse plane for the tibia rotating muscles and a proper biomechanical index for these muscles should be determined [3]. Assessment of the usefulness of the H/Q ratio should be extended by adding: multijoint and multiplane measurements, joint mobility measurements, the patient's subjective assessment, other functional locomotion and all-body fitness tests, and neuromuscular coordination measurements such as those taken while running or jumping combined with a clinical assessment of the patient [24]. The strength of the study was that it used a precise physiotherapy regimen for assessment in the ACLR group [2]. All the patients being assessed underwent six months of physiotherapy according to a uniform protocol at one rehabilitation center. They were monitored in the same conditions and with the same time intervals after the surgery. The measurements were performed both under conditions of maximal isometric tension and under isokinetic testing. Dynamic conditions are an important aspect of this study and similar approaches have rarely been mentioned in the literature [4].

\section{Conclusions}

The H/Q ratio combined with RIT, RPT, LSI, $\mathrm{ROM}$ is useful in monitoring the effectiveness of a supervised physiotherapy regimen performed regularly for 6 months by patients after ACLR who want to return to the sport. Most of those biomechanical parameters for the flexor and extensor muscles of operated knee joints were similar to those observed in the non-operated knee joints and the control group.

\section{Conflicts of interest statement}

The authors declare no conflicts of interest, as all of the expenses were covered by the College of Physiotherapy in Wroclaw and the Center of Rehabilitation and Medical Education in Wroclaw, Poland.

\section{References}

[1] Bijur P.E., Silver W., Gallagher E.J., Reliability of the visual analog scale for measurement of acute pain, Acad. Emerg. Med., 2001, 8 (12), 1153-1157.

[2] CZAMARA A., Moments of muscular strength of knee joint extensors and flexors during physiotherapeutic procedures following anterior cruciate ligament reconstruction in males, Acta Bioeng. Biomech., 2008, 10 (3), 37-44.

[3] Czamara A., Królikowska A., Two-Plane Assessment of Knee Muscles Isometric and Isokinetic Torques After Anterior Cruciate Ligament Reconstruction, Med. Sci. Monit. 2018, 14 (24), 4882-4893, DOI: 10.12659/MSM.908411.

[4] CZamara A., Królikowska A., SzuBa Ł., The influence of exercises under isokinetic conditions on heart rate in males aged between 40 and 51, Acta Bioeng. Biomech., 2011, 13 (3), 95-104.

[5] Czamara A., Tomaszewski W., Bober T., Lubarski B., The effect of physiotherapy on knee joint extensor and flexor muscle strength after anterior cruciate ligament reconstruction using hamstring tendon, Med. Sci. Monit., 2011, 17 (1), 35-41, DOI: 10.12659/MSM.881327.

[6] Dauty M., Menu P., Fouasson-Chailloux A., Ferréol S., DuboIs C., Prediction of hamstring injury in professional soccer players by isokinetic measurements, Muscles Ligaments Tendons J., 2016, 6 (1), 116-123, DOI: 10.11138/mltj/ 2016.6.1.116.

[7] De Ste Croix M., El Nagar Y.O., Iga J., Ayala F., James D., The impact of joint angle and movement velocity on sex differences in the functional hamstring/quadriceps ratio, Knee, 2017, 24 (4), 745-750, DOI: 10.1016/j.knee.2017.03.012.

[8] El-Ashker S., Carson B.P., Ayala F., De Ste Croix M., Sex-related differences in joint-angle-specific functional hamstring-to-quadriceps strength ratios, Knee Surg. Sports Traumatol. Arthrosc., 2017, 25 (3), 949-957, DOI: 10.1007/ s00167-015-3684-7.

[9] Fischer F., Fink C., Herbst E., Hoser C., Hepperger C., BlANK C., GFÖLlER P., Higher hamstring-to-quadriceps isokinetic strength ratio during the first post-operative months in patients with quadriceps tendon compared to hamstring tendon graft following ACL reconstruction, Knee Surg. Sports Traumatol. Arthrosc., 2017, 21 (3), DOI: 10.1007/ s00167-017-4522-x.

[10] GoKeler A., Welling W., Zaffagnini S., Seil R., Padura D., Development of a test battery to enhance safe return to sports after anterior cruciate ligament reconstruction, Knee Surg. Sports Traumatol. Arthrosc., 2017, 25 (1), 192-199, DOI: $10.1007 / \mathrm{s} 00167-016-4246-3$.

[11] Grygorowicz M., MichalowsKa M., WalczaK T., Owen A., Grabski J.K., Pyda A., Piontek T., Kotwicki T., Discus- 
sion about different cut-off values of conventional hamstring to-quadriceps ratio used in hamstring injury prediction among professional male football players, PLoS One, 2017, 12 (12), DOI: 10.1371/journal.pone.0188974.

[12] Haillotte G., Hardy A., Granger B., Noailles T., KHIAMI F., Early strength recovery after anterior cruciate ligament reconstruction using the fascia lata, Orthop. Traumatol. Surg. Res., 2017, 103 (7), 1021-1025, DOI: 10.1016/ j.otsr.2017.07.013.

[13] Hannah R., Folland J.P., Smith S.L., Minshull C., Explosive hamstrings-to-quadriceps force ratio of males versus females, Eur. J. Appl. Physiol., 2015, 115 (4), 837-847, DOI: 10.1007/s00421-014-3063-y.

[14] Huang H., Guo J., Yang J., Jiang Y., Yu Y., Muller S., REN G., AO Y., Isokinetic angle-specific moments and ratios characterizing hamstring and quadriceps strength in anterior cruciate ligament deficient knees, Sci. Rep., 2017, 7 (1), DOI: 10.1038/s41598-017-06601-5.

[15] Kim H., LeE J., AhN S., PARK M., LeE D., Influence of Anterior Cruciate Ligament Tear on Thigh Muscle Strength and Hamstring-to-Quadriceps Ratio: A Meta-Analysis., PLoS One, 2016, 11 (1), DOI: 10.1371/journal.pone.0146234.

[16] Kyritsis P., Bahr R., Landreau P., Miladi R., WiTVROUW E., Likelihood of ACL graft rupture: not meeting six clinical discharge criteria before return to sport is associated with a four times greater risk of rupture, Br. J. Sports Med., 2016, 50 (15), 946-951, DOI: 10.1136/ bjsports-2015-095908.

[17] Lee D., Lee J., Jeong H., LeE S., Lack of Correlation between Dynamic Balance and Hamstring-to-Quadriceps Ratio in Patients with Chronic Anterior Cruciate Ligament Tears, Knee Surg. Relat. Res., 2015, 27 (2), 101-107, DOI:10.5792/ ksrr.2015.27.2.101.

[18] LeE J.W.Y., MoK K.M., Chan H.C.K., Yung P.S.H., Chan K.M., Eccentric hamstring strength deficit and poor hamstring-toquadriceps ratio are risk factors for hamstring strain injury in football: A prospective study of 146 professional players, J. Sci. Med. Sport., 2018, 21 (8), 789-793, DOI: 10.1016/ j.jsams.2017.11.017.

[19] Maurelli O., Bernard P.L., Dubois R., Ahmaidi S., PRIOUX J., Effects of pre-competitive preparation period on the isokinetic muscular characteristics in world class handball players, J. Strength Cond. Res., 2017, 20, DOI: 10.1519/ JSC.0000000000002199.
[20] Oliveira L.F., Verneque D., Menegaldo L.L., The influence of aging on the isometric torque sharing patterns among the plantar flexor muscles, Acta Bioeng. Biomech., 2017, 19 (1), 41-45, DOI: 10.5277/ABB-00540-2015-03.

[21] Oliveira V., Wiechmann S., Narciso A., Deminice R., Knee extension and flexion strength asymmetry in Human Immunodeficiency Virus positive subjects: a cross-sectional study, Braz. J. Phys. Ther., 2017, 21 (6), 434-439, DOI: 10.1016/j.bjpt.2017.06.010.

[22] Pellicer-Chenoll M., Serra-Anó P., Cabeza-Ruizc R., Pardo A., ARANDAR., GonZÁlez L.M., Comparison of conventional hamstring/quadriceps ratio between genders in level-matched soccer players, Rev. Andal. Med. Deporte., 2017, 10 (1), 14-18, DOI: 10.1016/j.ramd.2015.05.002.

[23] SeKIr U., ARABACI R., AKova B., Acute effects of static stretching on peak and end-range hamstring-to-quadriceps functional ratios, World. J. Orthop., 2015, 6 (9), 719-726, DOI: 10.5312/wjo.v6.i9.719.

[24] Shultz R., Silder A., Malone M., Braun H.J., Dragoo J.L., Unstable surface improves quadriceps: hamstring co-contraction for anterior cruciate ligament injury prevention strategies, Sports Health, 2015, 7 (2), 166-171, DOI: 10.1177/ 1941738114565088.

[25] Struzik A., Siemieński A., Bober T., Pietraszewski B., Ratios of torques of antagonist muscle groups in female soccer players, Acta Bioeng. Biomech., 2018, 20 (1), 153-158, DOI: $10.5277 / \mathrm{ABB}-00942-2017-02$.

[26] Vieira A., Alex S., Martorelli A., Brown L.E., Moreira R., BOTTARO M., Lower-extremity isokinetic strength ratios of elite springboard and platform diving athletes, Phys. Sportsmed., 2017, 45 (2), 87-91, DOI: 10.1080/00913847.2017.1302310.

[27] Weeling W., Benjaminse A., Seil R., Lemmink K., ZAFFAGINI S., GoKelER A., Low rates of patients meeting return to sport criteria 9 months after anterior cruciate ligament reconstruction: a prospective longitudinal study, Knee Surg. Sports Traumatol. Arthrosc., 2018, 3 (24), 3636-3644, DOI: 10.1007/s00167-018-4916-4.

[28] Yip Ka-Yan E., Chan W.L., Lie Wai-Hung CH., Wong Kwun-Hung K., Woo SiU-Bon, Wong WING-CH., Isokinetic Quadriceps and Hamstring Muscle Strength After Anterior Cruciate Ligament Reconstruction: Comparison Between Single-bundle and Double-bundle Reconstruction, Journal of Orthopaedics, Trauma and Rehabilitation, 2013, 17, 71-76, DOI: 10.1016/j.jotr.2013.05.004. 